\title{
A INCORPORAÇÃO DE TRATADOS INTERNACIONAIS: UMA ANÁLISE SOBRE AS CONSEQUÊNCIAS NO DIREITO INTERNO
}

\section{THE INTERNATIONAL TREATIES INCORPORATION: AN ANALYSIS OF THE CONSEQUENCES IN DOMESTIC LAW}

${ }^{1}$ Fabiano Derussi

\section{RESUMO}

Este trabalho objetiva uma abordagem bibliográfica sobre as consequências que a incorporação de tratados internacionais traz para o direito privado interno. Aborda as teorias monista e a teoria do pluralismo jurídico para em seguida demonstrar uma correlação com a chamada crise dos códigos e o suposto enfraquecimento do Estado. Em um segundo ponto trata da relação entre globalização do capital, economia e tratados internacionais. Após, explica-se como os tratados internacionais são incorporados ao Estado, para demonstrar suas consequências no direito interno, chegando à conclusão que os tratados introduzem novos conceitos e institutos ao direito nacional, internacionalizando o direito privado interno.

Palavras-chave: Tratados internacionais, Globalização, Internacionalização

\begin{abstract}
This paper objectify an approach bibliographic about the consequences that the incorporation of international treaties brings to the domestic private law. Addresses the monistic theory and the theory of legal pluralism to then demonstrate a correlation with the so-called crisis of the codes and the alleged weakening of the state. After explains the relationship between globalization of capital, economy and international treaties. After, it explains how international treaties are incorporated into the state to demonstrate its impact on domestic law and concluded that the treaties introduce new concepts and institutes of national law internationalizing the internal private law.
\end{abstract}

Keywords: International treaties, Globalization, Internationalization

\footnotetext{
${ }^{1}$ Professor e Mestrando em Direito pela Universidade Comunitária da Região de Chapecó - UNOCHAPECO,

Santa Catarina, SC. (Brasil). E-mail: derussiadv@yahoo.com.br
} 


\section{INTRODUÇÃO}

O novo mundo, globalizado, tem sido fruto de fenômenos sociais das mais diversas alçadas. Como não poderia ser diferente, o Direito também tem sofrido fortes reflexos advindos da globalização. Os Estados que outrora monopolizavam a produção normativa de uma nação agora se deparam com um pluralismo jurídico cada vez mais crescente, onde são levados a adaptar-se e consequentemente verem suas velhas estruturas cederem como uma rocha que sofre a ação do tempo.

Uma das formas que o Estado tem encontrado para este processo de adaptação tem sido os tratados internacionais, utilizados assegurar uma melhor regulamentação das relações ocorridas em âmbito internacional, trazendo harmonia, segurança jurídica e, assim, facilitando o comércio internacional.

Mas diante do conteúdo material que estes tratados trazem consigo, surge um problema que vem ganhando visibilidade com o passar do tempo e que agora é investigado: Quais as consequências que estes tratados trazem para o direito interno?

Assim, justifica-se a proposta de estudo ora apresentada justamente para chamar a atenção sobre os efeitos que estes tratados trazem para o direito pátrio, principalmente no direito privado econômico, que detém grande importância para o desenvolvimento social da população, bem como para a própria manutenção do Estado.

Para chegar à parte conclusiva do presente trabalho, observou-se o método investigativo bibliográfico, com coleta de informações em obras doutrinárias e artigos científicos. O tipo da pesquisa e a básica, pois visa a produzir novos conhecimentos, sem uma aplicabilidade imediata prevista, mas, também, será do tipo qualitativa, comprometida apenas com fenômenos jurídicos que ocorrem na sociedade.

Quanto a abordagem do tema, para facilitar a compreensão do leitor, incialmente objetivou-se conceituar as teorias monista e pluralista que dão uma explicação racional sobre a origem do ordenamento jurídico de um Estado, sem, contudo, esgotar o tema, como alias, em nenhum momento no presente artigo cogitou-se.

Em seguida, abordou-se o fenômeno da globalização, objetivando identificar fator determinante para a intensificação das relações internacionais, inclusive, mediante assinatura de tratados internacionais que facilitam o fluxo de relações jurídicas principalmente de natureza comercial.

Por fim, aborda-se especificamente os tratados internacionais e seus reflexos para o ordenamento jurídico nacional, com uma breve introdução de quais os requisitos para estes se 
tornarem norma do Estado brasileiro, para em seguida, então chegar-se ao objetivo principal discussão, que são os efeitos trazidos para o ordenamento jurídico interno.

\section{A INCORPORAÇÃO DE TRATADOS INTERNACIONAIS: UMA ANÁLISE SOBRE AS CONSEQUÊNCIAS NO DIREITO INTERNO}

\subsection{ESTADO COMO PRODUTOR SOBERANO DO DIREITO}

A partir do surgimento do Estado moderno, como consequência do contrato social, o Estado passa a ter a pretensão de ser a única fonte produtora do direito. A partir da Revolução Inglesa, Americana e Francesa, há uma definitiva afirmação de que o Estado apesar de também estar submisso a Lei, passa a ser a única fonte soberana de produção dela.

Embora lei e norma não se confundem, desde o nascedouro do Estado moderno até os dias atuais, principalmente nos países da Civil Law, o principal fruto de monopólio do Estado é a lei, ela é a principal fonte do Direito. Até mesmo as constituições, se consideradas um corpo de normas e princípios, não escapam das formalidades de criação e positivação que o Estado necessita para reconhecer seus preceitos.

“O Estado não só pretende criar o direito, mas também se afirmar como o único sujeito produtor do mesmo, com a consequência imediata e grave de se afirmar também como o único ente em condições de conferir uma regra social genérica” (GROSSI, 2010, p. 2). Mas este poder vai além, o Estado não só cria o direito como também o interpreta por meio de sua jurisdição, exercendo verdadeiro monopólio de poder regulamentar sobre a sociedade.

O poder privado de criar normas restringiu-se a diminuta relações negociais entre particulares, podendo estes exercer a liberdade de contratar livremente, desde que respeitadas as chamadas normas de ordem pública. Contudo, mesmo essa autonomia privada para a criação do seu próprio direito, ainda assim não se deve à omissão ou impotência do Leviatã, mas sim por mera delegação de poderes do mesmo, conforme explicava Norberto Bobbio (2008). Assim, novamente há uma confirmação de que o Estado, seja por meio direito por delegação, é a fonte principal do direito institucionalmente reconhecido.

Fruto deste monopólio uma das principais criações do Estado Moderno foram os códigos, que visavam criar um direito uniforme, destinado a todos os membros da sociedade indistintamente, um verdadeiro corpo legislativo que têm como objetivo prever todas as hipóteses possíveis do comportamento humano e atribuir-lhes um contra comportamento, seja ele omissivo ou comissivo, como ocorre em algumas normas de Direito Penal ou Direito Comercial. 
O processo de codificação foi em princípio a melhor caminho encontrado pelo novo regime, em detrimento do direito costumeiro e fragmentado que existia durante o período da Idade Média, época em que os feudos possuíam considerável autonomia normativa para disciplinar a vida dentro de seus domínios. O direito comercial entre as diferentes localidades, por exemplo, (lex mercatória) era fruto de práticas reiteradas e observadas independentemente de existência de um comando oficial.

Para Grossi (2010) o Príncipe medievar poderia ter máxima efetividade de poder, mas lhe faltava a psicologia do Soberano moderno em querer disciplinar todo o social. Enquanto o Estado Moderno é legislador o Príncipe medieval era preponderantemente juiz, mesmo que as vezes se arriscasse a fazer leis.

Assim, embora não se possa afirmar que na Idade Média não existiam leis oficiais, estas eram de número reduzido, ficando a cargo da própria sociedade regulamentar seus atos do cotidiano, o direito emergia de uma fonte costumeira como realmente ocorre em uma nascente de um rio, onde que a água brota da terra de baixo para cima. Na Idade Média, o direito também nascia de baixo para cima.

A este fenômeno moderno de criação e reconhecimento do direito unicamente pelo Estado, recebeu a denominação de monismo jurídico, ou seja, somente existe um ordenamento jurídico para cada Estado e cada Estado tem um ordenamento próprio. Este ordenamento somente é aquele oficialmente reconhecido e emanado do próprio Estado.

Embora o Estado Moderno já tenha mais de duzentos anos desde o seu surgimento e ter passado por profundas transformações, principalmente depois de duas Guerras Mundiais, verifica-se que ao menos nos países que adotam o Civil Law, a lei continua sendo a principal fonte do direito. Os códigos continuam existentes e importantes, abrangendo grandes conteúdos normativos.

Se analisada a Constituição Federal brasileira, embora intitulada como Constituição Cidadã, carregada de direitos e garantias estendidos aos cidadãos, verifica-se que a ideologia de fundo ainda é a mesma: A soberania nacional e monopólio do Estado na produção do Direito continuam intactos como eram originariamente nas teorias tradicionais.

$\mathrm{O}$ artigo $1^{\circ}$, inciso I, da Carta Magana brasileira ${ }^{2}$ traz como fundamento da nação a soberania nacional. No artigo $2^{\circ 3}$ traz a tripartição dos poderes, como engenhado por

\footnotetext{
${ }^{2}$ Art. $1^{\circ}$ A República Federativa do Brasil, formada pela união indissolúvel dos Estados e Municípios e do Distrito Federal, constitui-se em Estado Democrático de Direito e tem como fundamentos: I - a soberania; ${ }^{3}$ Art. $2^{\circ}$ São Poderes da União, independentes e harmônicos entre si, o Legislativo, o Executivo e o Judiciário
} 
Montesquieu, caracterizados pela produção, aplicação e interpretação e execução das leis, todos harmônicos entre si, pertencentes à União.

O próprio artigo $5^{\circ}$, caput $^{4}$ da Constituição Federal ao garantir a igualdade de todos indistintamente perante a lei, já traz em si um standart jurídico para a lei, para a norma escrita emanada do Estado. Embora o princípio da igualdade seja estendido a todas as relações sociais, permitindo-se tratamento desigual apenas quando o tratamento igualitário se revelar em uma verdadeira desigualdade, verifica-se que este entendimento é uma construção doutrinária e jurisprudencial, pois o constituinte manteve as mesmas ideologias do novo Estado Moderno pós Revolução Francesa.

O reflexo lógico desta soberania estatal, aflora em todos os campos do direito, seja ele privado ou público, até mesmo nas relações internacionais, o Estado tradicionalmente ocupa o papel central no acento das negociações, naquilo que os teóricos das relações internacionais chamam de teoria monista.

Assim, na sociedade internacional moderna, caracterizada tipicamente como interestatal, os Estados Nacionais soberanos ganham destaque, os quais além de representar legitimamente seu povo e, também, constituem o "núcleo de articulação política do sistema internacional e apresentam-se como o principal ator da sociedade internacional moderna." (BEDIN, 2001, p. 176)

Como forma de assegurar o império da lei, até mesmo nas relações internacionais em que o Estado seja parte, os tratados para serem incorporados e válidos em território nacional, especialmente no caso brasileiro, necessitam de chancela do poder legislativo, não bastando a mera assinatura pelo chefe do poder executivo para sua vigência e validade.

Uma vez passando pelo processo de incorporação, via de regra os tratados internacionais ingressam no ordenamento pátrio com status de lei ordinária. Se o tratado dizer respeito a Direitos Humanos, e desde que aprovados em cada casa do Congresso Nacional em dois turnos e por no mínimo três quintos dos votos de cada uma das casas, terá então o tratado status de emenda constitucional (art. $5^{\circ}, \S 3^{\circ}$, da Constituição Federal $)^{5}$.

\footnotetext{
${ }^{4}$ Art. $5^{\circ}$ Todos são iguais perante a lei, sem distinção de qualquer natureza, garantindo-se aos brasileiros e aos estrangeiros residentes no País a inviolabilidade do direito à vida, à liberdade, à igualdade, à segurança e à propriedade, nos termos seguintes:

${ }^{5} \S 3^{\circ}$ Os tratados e convenções internacionais sobre direitos humanos que forem aprovados, em cada Casa do Congresso Nacional, em dois turnos, por três quintos dos votos dos respectivos membros, serão equivalentes às emendas constitucionais.
} 
Mas, de qualquer forma, não é admitido do ordenamento jurídico brasileiro que lei, tratados, sentenças estrangeiras, ou quaisquer outras declarações de vontade feitas fora do brasil, tenham reconhecimento jurídico aqui, quando ofenderem a soberania nacional, os bons costumes nacionais e a ordem pública (art. 17 da Lei 4.657/1942) ${ }^{6}$

Para coroar de vez a lei, os Estado brasileiro, adepto do sistema Civil Law, ainda limita a atividade jurisdicional do Poder Judiciário dizendo que apenas quando a lei for omissa, o juiz poderá decidir o caso de acordo com a analogia, os costumes e os princípios gerais do Direito. (Art. $4^{\circ}$ da Lei 4.657/1942) ${ }^{7}$.

Contudo, fenômenos sociais, econômicos e científicos propiciam transformações profundas nos comportamentos sociais de modo geral, não só no Brasil, mas em todo o mundo. Não só fluxos culturais, mas também econômicos, passaram a intensificar-se crescentemente, especialmente após as duas grandes guerras. Passou a existir uma crescente troca de experiências entre os diferentes Estados, fato que foi denominado de teoria da interdependência entre nações.

Houve o início de uma nova era; Os modelos internacionais tradicionais estão em processo de corrosão; As ideias e soluções tradicionais mostram-se fracassadas e sem efeito. O mundo se tornou interdependente tanto no campo da economia, quanto na tecnologia, comunicação e, também, nas aspirações humanas. O Estado dependente, caracterizado por vulnerável a forças externas, torna-se agora interdependente, ou em dependência mútua. "En política mundial, interdependencia se refiere a situaciones caracterizadas por efectos recíprocos entre países o entre actores en diferentes países”. (KEOHANE; NYE, 1988, p. 22)

Esta interdependência econômica e política entre Estados, é a marca mais comum de um fenômeno tido por recente na história da humanidade, a globalização. Mas, apesar da globalização como é conhecida contemporaneamente ser considerada um fenômeno de menos de pouco mais de um século, ela apenas representa a intensificação de um fenômeno muito antigo da humanidade: $\mathrm{O}$ intercâmbio entre os diferentes povos, seja por meio da guerra, ou por meio do comércio.

\subsection{A GLOBALIZAÇÃO DA ECONOMIA}

\footnotetext{
${ }^{6}$ Art. 17. As leis, atos e sentenças de outro país, bem como quaisquer declarações de vontade, não terão eficácia no Brasil, quando ofenderem a soberania nacional, a ordem pública e os bons costumes.

${ }^{7}$ Art. $4^{\mathrm{o}}$ Quando a lei for omissa, o juiz decidirá o caso de acordo com a analogia, os costumes e os princípios gerais de direito.
} 
Não obstante o Estado chamar para si o monopólio normativo em tempos modernos, algumas práticas comerciais revelariam desde já que tal intenção encontraria embaraços em sede de contratos internacionais.

Isso porque além do direito estatal interno não conseguir atender satisfatoriamente ambas as partes inseridas em diferentes sistemas jurídicos, as mudanças sociais ocorridas especialmente após o século XX, advindas em parte como consequência do desenvolvimento de novas tecnologias de comunicação, facilitaram e com isso intensificaram as relações entre pessoas do mundo todo.

Além de informação, há tocas culturais que acabam influenciando hábitos e costumes das pessoas, que passam a se comportar e agir de acordo com uma noção de tempo e espaço completamente distintos do que fariam em tempos anteriores.

Muda não só o comportamento cultural, mas também o de consumo e de investimento das pessoas. A leitura do mundo passa a ser outra, mais completa e mais rápida, embora possa haver em alguns casos uma verdadeira confusão pelo excesso de informação. Mas, mesmo assim o paradigma já é outro.

Diante da mudança social, o Estado não pode permanecer estanque, ele não pode ficar alheio a tais mudanças, especialmente em razão da crescente vulnerabilidade de suas fronteiras, que não são apenas físicas. Ianni (1996), explica que após a Segunda Guerra Mundial e com o final da Guerra Fria, houve uma própria alteração no significado do chamado Estado Nação, especialmente em razão da globalização.

Isso ocorre especialmente em razão dos projetos nacionais marcadamente capitalistas, caracterizados pelo liberalismo econômico que abriram espaços para as chamadas empresas transnacionais, corporações multilaterais, que acabam por influenciar as próprias decisões políticas dos Estados.

A exemplo, a própria moeda dos Estados toram-se um reflexo da moeda mundial. Os fatores de produção, como o capital, a tecnologia e a força de trabalho, organizam-se e se reproduzem de acordo com uma ordem mundial. O próprio Estado acaba se aparelhando segundo as exigências do mercado mundial.

Embora os comentários de Ianni (1996) tragam uma visão de que existe, corporações internacionais que além de estar fora do alcance dos Estados, ainda o torna submisso, o tema é bastante complexo e de suma importância apesar de não ser o objetivo, do presente estudo.

A primeira questão é a da soberania nacional. Ora, se os Estados são levados a tomar decisões pautadas em critérios econômicos globais, muitas vezes, inclusive, sob forte 
necessidade de corresponder com a expectativa de mercado e não com seus projetos de governo, é possível constatar o quanto pode ser frágil o conceito de soberania especialmente em Estados economicamente dependentes.

Embora não possa ser apontada uma sansão direta e específica para o Estado que não se comporte conforme a expectativa da sociedade econômica internacional, o descrédito e a insegurança gerados terá consequências tão prejudiciais ou até maiores que uma sansão expressa. Por isso, novamente há uma corrosão do tradicional conceito de soberania nacional.

Mas, sob outro ponto de vista, o Estado-moderno formalmente ainda está revestido de soberania como sempre foi desde o seu surgimento. Assim, os estados legislam por opção política, mas não por imposição de um organismo internacional ou de outro Estado, contudo, a teoria e a prática podem ganhar contornos distintos, não há como mascarar que a globalização do capital não afeta as políticas econômicas dos Estados.

Oliveira (2005), assevera que a globalização do capital também levou a globalização da produção; e nesse passo, vão se globalizando as instâncias jurídicas e políticas, as instituições e os próprios padrões socioculturais, produzindo, assim, o que denominou de processo civilizatório do capitalismo.

Este processo civilizatório do capitalismo tratado por Oliveira, obviamente se dá a partir do centro para a periferia, ou seja, são os países desenvolvidos que influenciam os países em desenvolvimento, em uma verdadeira relação de dependência dos últimos. Apesar da dependência ter se relativizado nas últimas décadas, podendo ser percebido uma interdependência entre nações, especialmente em razão da globalização ter levado certo desenvolvimento a um número maior de países, ainda assim a dependência ainda é um fato presente.

Por meio da dependência, criam-se situações de subdesenvolvimento e de dominação que ocorre de diversas formas e assume várias características. Possui ela orientação direta nos grupos produtores e consumidores. "Essa situação supõe nos casos extremos que as decisões que afetam a produção ou o consumo de uma economia dada são tomadas em função da dinâmica e dos interesses das economias desenvolvidas [...]" (CARDOSO; FALETTO. 1975, p. 26)

Atualmente, a dependência econômica dos hoje chamados países emergentes, ainda não desapareceu. Muitas das decisões soberanas dos Estados são tomadas para a manutenção de certas alianças comerciais, inclusive na elaboração e incorporação de um aparato normativo estruturante destas relações. 
Mas, o fenômeno explicado acaba por trazer consequências não só jurídicas e econômicas, mas também sociais, pois o próprio comportamento das pessoas vai tomando contornos em conformidade com estratégias políticas e econômicas globais, que inclusive não são mais frutos de organismos isolados, mas sim das estruturas conectadas em rede.

Para Oliveira (2015), operando em rede o capital financeiro pode ser investido de modo global, nos mais diversos setores ou atividades, como serviços, esportes, transporte, indústria, comércio, etc.

E mais, além do capital poder ser investido nas mais variadas partes do globo, isto ocorre de forma extremamente rápida, facilitando, inclusive, a especulação do capital. Como pode ser investido de forma rápida, também pode ser retirado com a mesma velocidade, criando, assim, investidores de ocasião.

Estas novas características do mundo globalizado tem mudado significativamente a forma de pensar os problemas mundiais, regionais e locais. Neste ambiente, o Estado, não consegue manter-se dentro de suas estruturas tradicionais. Suas fronteiras estão cada vez mais apagadas, e seus códigos não conseguem acompanhar a arrojada dinâmica social.

\subsection{A CRISE DOS CÓDIGOS X PLURALISMO JURÍDICO}

Diante de tão acentuadas mudanças ocorridas a partir de meados do Século XX, surgem interessantes fenômenos no campo político e jurídico. Um deles é a tentativa do Estado em manter sua hegemonia jurídica como produtor do direito por meio da lei e das noras estatais. Desprende um esforço sempre crescente para que o monismo jurídico mantenha-se o mais integro possível.

Por outro lado, surgem paralelamente ao ordenamento jurídico do Estado, outros ordenamentos, que inegavelmente também possuem importância social, já que independente do reconhecimento do Estado são respeitados pela sua população, ou seja, são eficazes mesmo que eventualmente careçam de reconhecimento por parte do soberano. Tal fenômeno vem contrapor a teoria do monismo jurídico e ficou batizada como teoria do pluralismo jurídico.

A tentativa do Estado manter o monopólio da produção do direito acaba por causar um certo enfraquecimento dos códigos, já que estes seriam para o Estado moderno um corpo legislativo perfeito, capaz de prever todas as condutas possíveis e a elas trazer um disciplinamento desejado pelo Soberano.

Grossi (2007), vê nos códigos a ideia de um fruto extremo da lei, marcado pelo monismo jurídico que classifica a lei no topo de qualquer outra fonte do direito, com 
hierarquia rígida sobre as posições inferiores, ocupando as últimas apenas um lugar servil.Nos Estados adeptos ao Civil Law, a pretensão do Código em regular o máximo de situações sociais possíveis, pode ser entendido como o núcleo do monismo jurídico, a expressão máxima do Estado como único produtor do direito e a de um direito denso e unitário.

Porém, desde a publicação do Código Civil de Napoleão Bonaparte em 1804 na França, até os tempos contemporâneos da hera da globalização, as mudanças sociais foram inúmeras, e os códigos, rígidos, engessados, começam a ver-se insuficientes e estáticos demais em relação à velocidade das mudanças.

Além do monopólio em relação à criação do direito, verifica-se que o acesso a linguagem nele inseridas também não é para os leigos, criando, assim, também um monopólio quanto ao conhecimento e alcance do direito, condutas típicas de um Estado absolutista.

Mas, afora estes problemas antigos da lei, de modo geral, a velocidade da globalização está verdadeiramente esfacelando os Códigos. As relações de consumo, por exemplo, intensificaram-se a tal ponto que foi necessário que o Estado legislasse especialmente para ela, o Direito Comercial, por exemplo, alcançou tamanha complexidade que o legislador brasileiro simplesmente abandonou a adoção de um código específico para estas relações.

O Estado na tentativa de manter seu monopólio de poder e do direito está legislando cada vez mais fora dos códigos. A cada fato novo que mereça disciplinamento cria-se uma lei especial, um microssistema jurídico. Estas leis especiais contem disposições de esferas jurídicas múltiplas, são por isso ditas como complexas. Temas que antes eram tratadas em diplomas específicos e separados, como Direito Penal, Direito Civil e Direito Administrativo agora é inserido tudo em uma única lei para disciplinar um único tipo de relação jurídica.

Mesmo assim, as leis são morosas para se tornarem realidade. O processo legislativo é complexo e lento, principalmente em razão dos diferentes interesses políticos que coexistem dentro de um Poder Legislativo democrático, mas, as necessidades do capital é imediato. Para o capitalismo vige o velho jargão popular que diz "tempo é dinheiro".

Assim, o poder do Estado se mostra insatisfatório, parcialmente eficaz aos propósitos do seu surgimento e, de certo modo, ineficiente. Por isso, diz-se que ele está em crise. Embora não uma crise existencial necessariamente, mas uma crise estrutural. As velhas estruturas do Estado já não conseguem atender ao capitalismo e isso está dando azo a outro fenômeno, chamado de pluralismo jurídico. 
Wolkmer (2001) leciona que quando as regras formais clássicas de arranjos institucionais e de legitimidade liberais da burguesia tornaram-se inapropriados para atender o

grande número de demandas surgidas com as sociedades de massa, os movimentos sociais acabaram por dar início a uma política pluralista. Esta nova forma de organização que não está pautada em instituições, seria descentralizada, democrática e autossustentável.

O pluralismo jurídico é uma doutrina que tem percebido a coexistência de ordenamentos jurídicos, ou seja, num mesmo Estado podem existir mais de um ordenamento jurídico além daquele oficial. Estes ordenamentos paralelos podem ser tolerados pelo Estado, neste caso, pode até haver um reconhecimento dele por parte do Soberano. Mas, também, existem ouros sistemas à margem do estatal, e que são repelidos por ele, mas nem por isso deixam de ser um sistema e de ser observado pelos locais.

A questão do pluralismo jurídico também não é algo novo para o Estado moderno. Recente é a sua forma de abordagem. Sem regressar muito na história, os ordenamentos jurídicos paralelos aos oficiais existiam desde o período colonial, seja com os nativos, escravos ou colonos.

Quem retrata muito bem esta passagem é Boaventura de Sousa Santos (2014), para ele o pluralismo jurídico está presente já no período de colonialismo, pois nele coexistiam no mesmo espaço arbitrariamente unificado, chamado colônia, tanto o direito do Estado como também o direitos tradicionais que lá já existia. Era uma coexistência por vezes conflituosa, mas, também, em alguns casos comportou acomodações, citando como exemplo o indirect rule do colonialismo inglês.

Atualmente, o pluralismo jurídico continua existente, mas por motivos relativamente distintos. Como o Estado legalista não consegue atender a demanda normativa de diversos setores da atividade privada, surgem ordenamentos paralelos para disciplinar as relações entre os membros de determinada categoria profissional. E, também, é questionável se estes ordenamentos se formam por delegação Estatal ou não, mas, o presente trabalho não comporta tamanha discussão.

Pode ser mencionado como exemplo do fenômeno do pluralismo jurídico as normas técnicas emitidas pela Associação Brasileira de Normas Técnicas (ABNT). Verifica-se no caso da $\mathrm{ABNT}$ que se trata de uma associação que emite diretrizes técnicas sobre diversos setores profissionais e que são amplamente reconhecidas e aceites por tais setores, mesmo que não haja uma sansão em razão de sua não observância. A eficácia de tais normas técnicas se 
dá pela maciça adesão da comunidade científica justamente pelo caráter de seriedade que dá ao trabalho desenvolvido, sem necessidade de qualquer reconhecimento ou imposição estatal.

Isto demonstra que onde há uma comunidade haverá normas, e que o direito antecede a lei e ao próprio Estado. Assim, resta clarividente o fracasso do Estado em tentar ser detentordo monopólio normativo de seu povo. Grossi, ainda que falando sobre a Idade Média, traz um bom exemplo, quando afirma que primeiro existe o direito, depois é que vem o poder político. Na Idade Média, o direito estava entranhado na sociedade, "como se fosse uma ossada secreta, estrutura escondida dessa”. (2007, p. 29)

É claro que o Estado sempre soube disso, então o que ele tem feito é tentar legislar o máximo possível para eliminar todos os ordenamentos paralelos possíveis, atitude que em tempos de globalização, gera uma verdadeira inflação legislativa. Mas, quando não for possível ou não for de seu interesse intervir, o Estado mantem-se inerte frente a tais ordenamentos paralelos. E quando tais ordenamentos forem subversivos ou contrários a ordem pública estatal, procura extingui-los, inclusive, usando a força policial.

Mas o ponto que interessa ao presente trabalho é investigar um pluralismo jurídico que vem de fora para dentro do Estado, este pluralismo geralmente surge para tratar de assuntos privados, e acaba sendo incorporado pelo Estado por meio de tratados, embora possa subsistir sem a chancela estatal, como é o caso do costume.

Para Glitz (2014) o pluralismo jurídico extrapola o limite das fronteiras nacionais. Há normas internacionais de diversas espécies e finalidades que acabam influenciando o ordenamento jurídico interno, independente do consentimento do Estado.

O fato é que com a globalização do capital e do comércio internacional surge um fenômeno perfeitamente previsível. Se existe relações jurídicas para fora das fronteiras das nações, também existirá um direito que foge ao alcance da regulamentação Estatal isolada.

Novamente, os estados nacionais são levados por necessidade econômica, ou por necessidade de afirmar sua hegemonia legislativa, a celebrar tratados internacionais com seus principais parceiros comerciais para então disciplinar como se resolverá e qual direito será aplicado quando eventualmente houver litígio entre seus súditos.

Ocorre que muitas vezes o Estado adere a determinado tratado e incorpora-o ao seu ordenamento pátrio sem sequer ter participado das rodadas de negociações. Ou mesmo que venha a participar, um tratado sempre será uma espécie de acordo com concessões mútuas. Assim, um ordenamento que era paralelo ao Estatal, passa a fazer parte dele. 
O fenômeno é interessante pelo fato de que tecnicamente não há como se falar em pluralismo jurídico em âmbito de tratados internacionais, já que quando incorporados pelo Estado passam a fazer parte dele. Por outro lado, o Estado incorpora uma cultura que não é sua, incorpora um ordenamento que não era o seu, tendo a doutrina tratado de tal fenômeno como sendo um "transplante jurídico". Mas, este é outro assunto que merece uma discussãoaparte. Por hora, o foco será em relação aos tratados internacionais, que é apenas uma das faces de tais transplantes.

\subsection{OS TRATADOS INTERNACIONAIS COMO FERRAMENTA PARA O COMÉRCIO INTERNACIONAL}

Com a massificação das relações comerciais internacionais, ocorre um fenômeno de certa forma natural, mas não inocente, de intercâmbio de experiências e conhecimento entre as diversas culturas sociais. Destes intercâmbios, que também são comerciais, algumas vezes ocorrem litígios, que de alguma forma precisam ser solucionados.

Nesta senda, ocorrendo o litígio, a primeira grande questão que surge é qual lei será aplicada ao caso. Mesmo as partes podendo optar por submeter o eventual litígio a uma forma extrajudicial de solução, como a arbitragem, por exemplo, deve ser lembrado que nem toda contenda privada tem viabilidade de julgamento em âmbito extrajudicial.

Esta conjuntura de incerteza quanto à lei aplicável ao contrato, gera insegurança jurídica, pois não permite uma correta análise de riscos pelos contratantes. Obviamente, que em casos assim, cada uma das partes sempre buscará que sejam aplicadas as normas que lhes parecer mais vantajosas.

Insegurança jurídica nas relações comerciais, principalmente internacionais, é sinônimo de desestimulo e retração dos negócios, além de encarecer os contratos realizados, trazendo consequências não só para a sociedade, mas também para o próprio Estado, já que sobrevive de tributos.

Atentos a tais circunstâncias, os Estados procuram estreitar relações com os seus principais parceiros comerciais, objetivando criar mecanismos facilitadores para a continuidade do comércio e ao mesmo tempo preservar sua soberania. Geralmente utiliza-se de instrumentos unificadores e harmonizantes de normas, as quais passam a ser comuns aos Estados signatários. 
Esta unificação do direito comercial, que ocorre especialmente por meio dos tratados internacionais, implica em incorporar ao ordenamento jurídico interno, normas e princípios próprios de determinada matéria. Lima (2008, p. 116) entende que "a unificação do direito privado representa a superação do contraste entre normas jurídicas conflituais ou substantivas, em que a legislação doméstica passa a ser substituída por regras uniformes incidentes sobre uma questão específica."

Assim, como no ordenamento jurídico brasileiro, a incorporação de um tratado deve necessariamente passar por um processo próprio de incorporação, que ao final, via de regra aofinal terá força de lei ordinária, o Estado consegue atender suas necessidades de atualização jurídica, sem contudo, perder seu monopólio legislativo.

Como o tratado passa a viger em nosso ordenamento jurídico com força de lei ordinária, ficam submetidos, ao princípio da lex posterior derrogat priori. Essa foi a interpretação, dada pelo Supremo Tribunal Federal do recurso extraordinário no 80.004 , de 1977, (MEDEIROS, 2007).

Mas, ressalta-se que cabe privativamente ao Presidente da República não só celebrar os tratados internacionais, mas, também, negociar eventuais clausulas do acordo (art. 84, VIII da Constituição Federal). Também, incumbe unicamente ao chefe do Poder Executivo após assinado o tratado, enviá-lo ao Congresso Nacional para sua ratificação, havendo, assim, uma ampla confirmação da adesão do Estado signatário.

Desta forma, pode um tratado ser assinado e permanecer anos sem que seja incorporado ao ordenamento jurídico nacional, já que no Brasil, a aprovação pelo Poder Executivo é obrigatória para a incorporação de qualquer tratado internacional.

No Brasil, há toda uma preocupação para a incorporação de acordos internacionais que vem desde os tempos do Primeiro Reinado, por isso o chefe do poder executivo não tem poderes para sozinho assumir compromissos gravosos ao país. A experiência negativa daquela época forçou que os legisladores do império aprovassem os compromissos externos enquanto o país fosse exercido por uma Regência Permanente. (MEDEIROS, 2007)

Concluindo o raciocínio, sem abrir mão de sua soberania e do controle legislativo, o Estado encontrou nos tratados internacionais uma forma tecnicamente satisfatória para manter o monopólio da regulamentação social, facilitando o comércio internacional, fortalecer a economia interna e propiciar, também, arrecadação aos cofres públicos.

Ocorre que com a incorporação de tratados internacionais às vezes surgem certos fenômenos que fogem à previsão estatal, como se fossem uma espécie de efeitos colaterais, 
que mesmo não sendo indesejados, paulatinamente transformam o Direito interno de um país mesmo fora do âmbito de aplicação da nova legislação.

\subsection{CONSEQUÊNCIAS DOS TRATADOS INTERNACIONAIS}

$\mathrm{Na}$ tentativa de manter seu monopólio legislativo, conforme explicado pela teoria monista, muitas vezes o Estado acaba por criar tratamentos legais embaraçosos pois flagrantemente desiguais em relação ao tratamento legislativo desprendido para relações jurídicas internas em comparação com o tratamento dado às relações jurídicas internacionais.Além disso, ainda pode ocorrer uma contradição na própria teoria monista. A este ponto, verifica-se que um Estado que se considera a única fonte normativa possível, deve guardar certa harmonia com as tradições seculares de uma nação, mas, ao incorporar um tratado o qual muitas vezes sequer participou da elaboração, pode estar inserindo em seu ordenamento normas e costumes que tradicionalmente nunca foram seu.

Quando isso ocorrer, é possível falar em pluralismo jurídico, já que a sociedade internacional, formada por diversos atores, literalmente criam normas para que os Estados incorporem em seu ordenamento, mesmo aquelas para facilitar o fluxo de capital no comércio internacional. Quando estas normas são incorporadas como se fossem genuinamente leis nacionais, verifica-se que a opção do Estado foi por apenas em aderir ao texto legal, mas não foi a fonte produtora do texto da norma, ou seja, o Estado cedeu à norma, não a criou necessariamente.

Em compasso com esta constatação Varella (2012, p. 107) constata que "As teorias monistas e dualistas não conseguem explicar de forma coerente todas as relações do Estado com o direito internacional." Existem muitas relações possíveis entre o ordenamento jurídico interno e a complexa sociedade internacional, podendo variar conforme a extensão das relações, como regionais, ou com a quantidade de atores envolvidos sendo elas então multilaterais, e, por fim, "conforme o tema ou o tempo da integração".

Ademais, a incorporação de tratados internacionais traz outras consequências, como a introdução de novas formas de interpretar princípios já existentes, além de trazer novos conceitos e novos instrumentos jurídicos, que paulatinamente internacionalizam o direito privado interno, no sentido de uniformizar de determinadas normas e institutos em consonância com normas internacionais específicas.

Ressalta-se que, apesar da uniformização do direito interno com o direito internacional não se dar unicamente por meio dos tratados, estes possuem importância ímpar 
na globalização do direito, pois são utilizados em larga escala ante a maior aceitação pela sociedade internacional.

Mas, a uniformização do direito interno com o internacional não significa necessariamente sua harmonização, pois a incorporação de um tratado acaba por criar novos conflitos jurídicos entre os dois ordenamentos. Exemplos existem muitos, desde como a norma incorporada será aplicada pelo Poder Judiciário local.

Lima (2008) explica que quando o juiz tem que aplicar uma legislação estrangeira que não faz parte do sistema jurídico interno, como uma lei do sistema common law sendo plicada em um país adepto do sistema civil law, terá que empregar conceito e métodos deinterpretação diferentes dos habituais. O direito de um sistema jurídico diferente do nacional pode não representar uma solução ideal, mesmo que corretamente interpretado, tornando, assim, o tema bastante complexo.

Além disso, ao ter que julgar contenda de direito internacional privado, mesmo existindo um tratado considerado lei interna ordinária, poderá a legislação de origem estrangeira não prever todas as situações hipotéticas possíveis nos conflitos desta natureza, fazendo, assim, o juiz brasileiro tenha que aplicar a lei genuinamente brasileira a uma relação jurídica de cunho internacional.

Assim, naquilo que o tratado internacional for omisso o Poder Judiciário brasileiro terá que aplicar subsidiariamente a norma brasileira de direito interno, podendo surgir conflito aparentes de normas, bem como interpretações típicas de conflitos de ordem interna, quando que em sede de uma relação jurídica internacional a interpretação deveria deve ser própria ou específica, justamente pela diferença existente entre normas internacionais e normas internas.

Ainda, pode ser verificada uma diferença de graduação hierárquica no tratamento dos costumes pelos tratados internacionais em relação ao tratamento dado a eles pelo direito interno. Enquanto no direito interno brasileiro o costume é apenas uma fonte subsidiária do direito, nos tratados internacionais, eles podem ser a fonte primária.

Glitz (2014), acrescenta que o costume no direito brasileiro, além de possuir fonte formal, também possui papel secundário em relação à lei. Assim, a lei deve prevalecer mesmo quando estiver em conflito com o costume, por mais longa tradição que o mesmo tenha.

Como exemplo do que se explana, tem-se a Convenção de Viena de 1980 (CISG), que foi incorporada recentemente no ordenamento jurídico brasileiro (2014). Nela o costume recebe tratamento diferenciado em relação ao ordenamento interno tradicional. 
$\mathrm{Na}$ seara dos costumes internacionais, como ocorre na CISG, seu papel extrapola a função de mera interpretação do negócio jurídico. Ele é fonte obrigacional e pode impor automaticamente aos contratantes algumas obrigações não previstas contratualmente, mas que possuem força normativa em razão do seu conteúdo consuetudinário (GLITZ, 2014).

Desta forma, podem ocorrer formas diferencias de solução para problemas idênticos dentro de um mesmo ordenamento jurídico, a depender da especialidade da matéria envolvida. Como visto, como os costumes comerciais internos podem ser classificados de forma diferente do costume comercial internacional, a hierarquia que cada um ocupará dentro dos critérios utilizados pelo Poder Judiciário na interpretação e aplicação da lei poderão ser distintas, trazendo soluções também diferenciadas.

Assim, poderá o Poder Judiciário se utilizar de direito interno para a resolução de conflitos de ordem internacional, ou, ainda, poderá se utilizar de institutos de direito Internacional para a resolução de casos puramente nacionais, restando neste ponto talvez o maior exemplo do fenômeno intitulado de internacionalização do direito privado.

Mesmo os tratados internacionais sendo incorporados com status de lei especial, ou seja, regulamente somente matérias bem delimitadas, teoricamente é possível que, usando analogia, os tribunais apliquem regras e conceitos internacionais para a resolução de conflitos internos, surgindo, assim, uma jurisprudência fundamentada em nestes novos paradigmas .

Este fenômeno acaba por paulatinamente trazer reflexos para o direito interno, que vagarosamente vai sendo igualmente uniformizado, por influência de normas internacionais, tendência esta que está recebendo a nomenclatura de "internacionalização do direito privado", especialmente pela adoção de conceitos e fórmulas externas, sendo que os casos mais recorrentes acontecem no direito contratual.

Glitz (2014), refere-se que a "internacionalização" dos contratos ocorre quando em contratos nacionais aplicam-se soluções oriundas de fórmulas internacionalmente consagradas, principalmente pelo uso do costume internacional.

Embora os Estados inicialmente resistam ao fenômeno, especialmente no direito privado, são notórios esforços internacionais, especialmente por parte de organismos internacionais, com função específica para estudar e criar normas e modelos de contratos padrões de ampla aceitação, com o fim de facilitar o comércio internacional. Como exemplo, cita-se a UNCITRAL (The United Nations Commission on International Trade Law).

Por fim, o fator determinante para estes esforços internacionais de uniformização ou internacionalização do direito privado é a globalização. Se fosse excluída a globalização do 
cenário, certamente a realidade seria outra. Mas, todas as evidências demonstram que este fenômeno de internacionalização do direito privado tende a se intensificar. Os Estados, por sua vez, cada vez mais utilizam dos tratados internacionais para incorporar ao seu ordenamento jurídico este direito uniforme, internacionalizado.

\section{CONCLUSÃO}

Com o desenvolvimento econômico e com a globalização, verifica-se que Estado já não consegue manter-se hegemônico quanto aspirava desde seu surgimento em manter o monopólio da produção legislativa de uma nação.

Especialmente nos países da Civil Law, o processo de descodificação do direito é um indício de que algo estava abruptamente mudando na política interna de cada Estado,justamente para atender uma crescente variedade de situações advindas do fenômeno da globalização que os tradicionais códigos já não conseguiam abarcar.

As fronteiras dos Estados parecem estar sofrendo constante redução em seu perímetro, justamente pela facilitação que o desenvolvimento tecnológico propiciou ao ser humano nas últimas décadas, fazendo então que intensificassem as relações internacionais, não só de Estados, mas também de toda a esfera social, especialmente a econômica.

Os Estados, fortes em seu objetivo de manterem-se íntegros enquanto único produtor de normas e da manutenção de um único ordenamento jurídico interno, acabam por regulamentar o maior número de situações sociais possíveis, inclusive as econômicas.

As relações econômicas, especialmente as internacionais, contudo, não conseguem ficar adstritos unicamente à vontade dos Estados, por mais que aqueles mais poderosos economicamente exerçam influência nos Estados mais dependentes. Assim, o Direito tem sido estudado, investigado, sob a ótica internacional e muitas vezes o resultados destes estudos ou tratativas são a celebração de verdadeiros acordos entre Estados, os tratados internacionais.

Foi possível verificar também que estes tratados, não dizem respeito unicamente a um direito Estatal fechado, mas é resultado de diferentes fontes de poder, inclusive as não estatais como decorrentes das empresas transnacionais, por exemplo.

Estas normas internacionais, após incorporadas aos ordenamentos dos diferentes estados, passam, então, a exercer efeitos não só nas relações específicas para as quais eles nasceram, mas também acabam refletindo no próprio direito interno de cada país, mudando conceitos, trazendo outros novos, e assim, literalmente internacionalizando o direito interno. 
Assim, por mais que o Estado afirme sua soberania e hegemonia normativa, verifica-se que estas estão cada vez menos restritas unicamente a vontade estatal, mas sim, são frutos de uma necessidade de adaptação a uma globalização capitalista, com perspectiva duradoura no seio da sociedade internacional.

\section{REFERÊNCIAS BIBLIOGRÁFICAS}

BEDIN, Gilmar Antonio. A sociedade Internacional e o século XXI: em busca da construção de uma ordem judicial justa e solidária. Ijuí: Ed. Unijuí, 2001.

BOBBIO, Norberto. Teoria da norma jurídica. Trad. Fernando Pavan Bapista e Ariani Bueno Sudatti. 4. ed. Bauru: Edipro, 2008.

BRASIL. Decreto no 8.327 , de 16 de outubro de 2014. Promulga a Convenção das Nações Unidas sobre Contratos de Compra e Venda Internacional de Mercadorias - Uncitral, firmada pela República Federativa do Brasil, em Viena, em 11 de abril de 1980. Presidência da República: [Brasília], [2014]. Disponível em: <http://www.planalto.gov.br/ccivil_03/ http://www.planalto.gov.br/ccivil_03/_Ato2011-2014/2014/Decreto/D8327.htm_Ato20112014/2014/Decreto/D8327.htm>. Acesso em: 16 ago. 2015.

Constituição da Republica Federativa do Brasil de 1988. Presidência da República: [Brasília],[1988].Disponívelem:<http://www.planalto.gov.br/ccivil_03/constituicao/Constituic aoCompilado.htm>. Acesso em: 11 set. 2015.

Decreto-lei $n^{\circ} 4.657$, de 4 de setembro de 1942. Lei de Introdução às normas de

Direito Brasileiro. Presidência da República: [Brasília], [1942]. Disponível em: < http://www.planalto.gov.br/ccivil_03/decreto-lei/Del4657compilado.htm>. Acesso em: 11 set. 2015.

CARDOSO, Fernando Henrique; FALETTO, Enzo. Dependência e desenvolvimento na América Latina. 3.ed. Rio de Janeiro: Zahar, 1993.

DIMITRUK, Hilda Beatriz (Org). Cadernos Metodológicos: Diretrizes do trabalho científico. Chapecó: Argos, 2012.

GABSCH, Rodrigo D’Araujo. Aprovação dos tratados internacionais pelo Brasil: possíveis opções para acelerar seu processo. Brasília: Fundação Alexandre de Gusmão, 2010.

GLITZ, Frederico Eduardo Zedenin. Contrato, globalização e Lex Mercatória: Convenção de Viena 1980 (CISG), Princípios Contratuais Unidroit (2010) e Inconterms (2010). Rio de Janeiro: Clássica, 2012.

GROSSI, Paolo. O direito entre poder e ordenamento. Trad. Arno Dal Ri Júnior. Belo Horizonte: Del Rey, 2010. 
Boiteux, 2007.

IANNI, Octavio. Teorias da Globalização. 3. ed. Rio de Janeiro: Civilização Brasileira, 1996.

KEOHANE, Robert O.; NYE, Joseph S.; Poder e independência: la política mundial en tansición. Trad. Heber Cardoso Franco. Buenos Aires: Grupo Editor Latinoamericano, 1988.

LIMA, João André. A harmonização do direito privado. Brasília: Fundação Alexandre de Gusmão, 2007.

MEDEIROS, Antonio Paulo Cachapuz de (org). Jornadas de Direito Internacional Público no Itamaraty (2005, Brasilia, DF): Desafios do direito internacional Contemporâneo. Brasília: Fundação Alexandre de Gusmão, 2007.

MONTESQUIEU, Charles de Secondat, Baron de. O espírito das leis: As formas de governo, a federação, a divisão dos poderes. Trad. Pedro Vieira Mota. 9. ed. São Paulo: Saraiva, 2008.

OLIVEIRA, Odete Maria de. Teorias globais e suas revoluções: Impérios de poder e modos de produção. v.2, Ijuí: Ed. Unijuí, 2005.

SANTOS, Boaventura de Souza. O direito dos oprimidos: Sociologia crítica do direito/ parte 1. São Paulo: Cortez, 2014.

VARELLA, Marcelo. Internacionalização do Direito: Direito Internacional, globalização e complexidade. Brasília: Uniceub, 2013.

WOLKMER, Antonio Carlos. Pluralismo Jurídico: Fundamentos de uma nova cultura no Direito. 3. ed. São Paulo: Alfa-Omega, 2001. 